\title{
Evaluation Nursing Students' Views of Improved Competence Development after Clinical Supervision: An Educative Approach to the WHO Patient Safety Model
}

\author{
Anne Lyberg*, Kirsten Eika Amsrud, Elisabeth Severinsson \\ Centre for Women's, Family and Child Health, Faculty of Health Sciences, Buskerud \& Vestfold University \\ College, Kongsberg, Norway \\ Email: $\underline{\text { Anne.Lyberg@hbv.no }}$
}

Received 15 July 2015; accepted 18 August 2015; published 21 August 2015

Copyright (C) 2015 by authors and Scientific Research Publishing Inc.

This work is licensed under the Creative Commons Attribution International License (CC BY).

http://creativecommons.org/licenses/by/4.0/

(c) (i) Open Access

\begin{abstract}
Bachelor of Science Nursing (BSN) students' education comprises both theories and practical aspects. Access to resources is required for the development of a professional identity, which includes gaining technical knowledge and receiving feedback, guidance as well as social and emotional support from clinical supervisors. The aim of this study was to evaluate BSN students' views of professional development after clinical supervision (CS) during their undergraduate education. An additional aim was to illuminate how competence development was related to the WHO Patient Safety Educational Model. A cross-sectional study was conducted, in which CS was measured as part of a survey completed by a sample of nursing students after their clinical placement at two time-points, namely 2012 and 2013. Statistical descriptive and inferential analyses were used and differences in the responses between Time 1 and Time 2 compared. The benefit of CS for nursing students' competence development revealed a positive significant relationship between students' Interpersonal skills and the factor Improved care/skills. There were differences in terms of variables related to the Importance value of CS and Professional skills. The results can be used to inform undergraduate nursing education leaders, teachers and practice partners on individual, group and organisational level in order to enhance patient safety and highlight the importance of CS for BSN students' professional development.
\end{abstract}

\section{Keywords}

Clinical Supervision, Nursing Students, Patient Safety

${ }^{*}$ Corresponding author.

How to cite this paper: Lyberg, A., Amsrud, K.E. and Severinsson, E. (2015) Evaluation Nursing Students' Views of Improved Competence Development after Clinical Supervision: An Educative Approach to the WHO Patient Safety Model. Open Journal of Nursing, 5, 725-734. http://dx.doi.org/10.4236/ojn.2015.58075 


\section{Introduction}

Bachelor of Science Nursing (BSN) students' education comprises a theoretical and a practical part. The latter includes clinical supervision (CS) as well as systematic reflection on experiences of practical learning situations [1]. In BSN education, the development of practical professional skills is important [2]. Addressing the gap between the theory, i.e., what is taught in the University BSN education, and how things are done in practice, is a challenge for the development of education in the clinical setting [3]. Students need assistance when applying theoretical knowledge in the clinical setting. The primary cognitive process in CS is reflection, i.e., thinking back on clinical experiences in order to recount them as a means of deepening understanding and/or identifying areas for further improvement [4]. Reflection increases professional knowledge and the capacity to understand problems [5]. CS provides an opportunity for reflecting on clinical situations, as well as professional development [6]. A quantitative study of students' improvement in learning as a result of CS revealed personal growth, feelings of security, increased sensitivity to patient needs, willingness to assume greater responsibility in clinical settings and preparedness to listen [3]. Students' integration of knowledge was related to the development of a language that influences thinking and serves as a model for communication, thus enabling reflection on various problems and creating an awareness of the concepts and phenomena inherent in nursing care and values [3]. Studies conducted by the present research team identified the following effects of student nurse supervision; increased understanding of patient needs, preserving patients' integrity and ensuring participation by patients and family members [7] [8]. These findings emphasize the potential of CS to contribute to personal growth and a caring attitude towards patients, thereby strengthening the development of skills essential for patient safety [9].

\subsection{The WHO Patient Safety Model and Competence Development}

The focus on quality and safety education for nurses has increased in recent years [10]. Patient safety can be defined as the reduction of risk and unnecessary harm associated with healthcare to an acceptable minimum [11]. Patient safety is a discipline that applies safety science methods in the healthcare sector with the goal of achieving a reliable healthcare delivery system [12].

The WHO [11] Patient Safety Curriculum Guide: Multi-professional Edition, is a comprehensive guide to facilitating effective capacity building in patient safety education provided by academic healthcare institutions. It contains educational frameworks and features a variety of concepts and methods for teaching and assessing patient safety. The topics in the WHO Patient Safety Curriculum Guide [11] were selected from an evidence-based Australian Patient Safety Education Framework [13], which contains seven learning categories; Communicating effectively, Using Evidence, Adverse events, Working safely, Being ethical, Learning and teaching and Specific issues such as prevention of infections. The learning categories have 22 topics with three learning domains in each topic; Knowledge, Skills and Behaviours/Attitudes (KSAs). The WHO Patient Safety Curriculum Guide [11] also refers to the Canadian framework entitled; The Safety Competences-Enhancing patient safety across health professions (CPST) [14], which identifies the knowledge, skills and attitudes required by all healthcare professionals. Six domains of competence are identified; Contribute to a Culture of Safety, Work in Teams for Patient Safety, Communicate Effectively for Patient Safety, Manage Safety Risks, Optimize Human and Environmental Factors and Recognize, Respond to and Disclose Adverse Events [14].

Students’ patient safety knowledge must be strengthened throughout their entire education and training. Education about patient safety skills and behaviours should begin as soon as a student enters a hospital, clinic or health service. By encouraging students to treat each individual patient as a unique human being and use their knowledge and skills carefully, the students themselves can serve as role models for others in the healthcare system [11]. Studies of the relationship between patient safety and CS are scare and therefore research that explores the professional development of BSN students in relation to patient safety outcomes as a result of attending CS during their clinical placement is required.

\subsection{Aim}

The aim of this study was to evaluate BSN students' views of professional development after clinical supervision (CS) during their undergraduate education. An additional aim was to illuminate how competence development was related to the WHO Patient Safety Educational Model. 


\section{Methods}

\subsection{Design}

A cross-sectional study design was used to evaluate BSN students' views of their professional development [15].

\subsection{Sample and Data Collection}

The study was based on a non-probability convenience sample of 66 second level and 59 third level BSN students who attended supervision during their clinical education [15]. Students who participated in the first round of data collection were included. Although most of the students responded on the two occasions, the data were not matched to each individual student. The questionnaires, cover letter and consent form were placed in an envelope and distributed by nursing teachers to those who agreed to participate and subsequently returned to one of the authors. The teachers from the university college were not responsible for assessing the students in this part of the study programme. Demographic characteristics are presented in Table 1.

Table 1. Demographic characteristics of the BSN students at Time 1 and Time 2.

\begin{tabular}{|c|c|c|}
\hline & Time $1 \mathrm{~N}=66$ & Time $2 \mathrm{~N}=59^{*}$ \\
\hline Age, years, med $\left(q_{1}-q_{3}\right)$ & $24(22-30)$ & $25(23-31.5)$ \\
\hline Female sex, No \% & $61(93.8)$ & $54(93.1)$ \\
\hline Previous work experience & $38(57.6)$ & 35 (59.3) \\
\hline Female supervisor, No \% & $59(89.4)$ & $49(83.1)$ \\
\hline \multicolumn{3}{|l|}{ Supervision frequency, No \% } \\
\hline Daily & $31(47.7)$ & $23(39.7)$ \\
\hline Every week & $26(40.0)$ & $21(36.2)$ \\
\hline Every second week & $6(9.2)$ & $10(17.2)$ \\
\hline Every month & $2(3.1)$ & $4(6.9)$ \\
\hline \multicolumn{3}{|l|}{ Supervising location, No \% } \\
\hline During work situations & $23(34.8)$ & $19(32.8)$ \\
\hline In a separate room & $5(7.6)$ & $7(12.1)$ \\
\hline Both & $38(57.6)$ & $32(55.2)$ \\
\hline \multicolumn{3}{|l|}{ Supervision context, No \% } \\
\hline Individually & $39(59.1)$ & $40(69.0)$ \\
\hline In a group & $4(6.1)$ & $3(5.2)$ \\
\hline Both & $23(34.8)$ & $15(25.9)$ \\
\hline \multicolumn{3}{|c|}{ Supervision duration as previously agreed, No \% } \\
\hline Yes & $15(22.7)$ & $18(32.1)$ \\
\hline No & $51(77.3)$ & $38(67.9)$ \\
\hline \multicolumn{3}{|l|}{ Supervision per week } \\
\hline$<15$ minutes & $14(21.5)$ & $13(22.8)$ \\
\hline 15 - 30 minutes & $26(40.0)$ & 18 (31.6) \\
\hline 31 - 45 minutes & $9(13.8)$ & $12(21.1)$ \\
\hline 46 - 60 minutes & $4(6.2)$ & $6(10.5)$ \\
\hline \multicolumn{3}{|l|}{ Supervising sufficient, No \% } \\
\hline Yes & $32(48.5)$ & $32(54.2)$ \\
\hline No & $34(51.5)$ & $27(45.8)$ \\
\hline
\end{tabular}

*Due to missing responses $\mathrm{N}$ varies between 66 and 59. 


\subsection{Research Questionnaires}

A package of three standardized instruments was used to measure key variables [9]. The BSN students' views of whether or not professional development had improved after attending CS in their clinical placement were assessed by means of a questionnaire that included demographic items, the Manchester Clinical Supervision Scale (MCSS) [16], the Effects of Supervision Scale (ESS) [17] and the Focus on Empowerment Supervision Scale (FESS) [7]. The MCSS consists of 36 items divided into six factors; trust/rapport; supervisor advice/support; improved care/skills; finding time; personal issues and reflection. The MCSS uses a five-point Likert scale ranging from 1 (strongly disagree) to 5 (strongly agree) as a response alternative for each item. The ESS [17] comprises 27 items divided into three sub-scales (Interprofessional-, Professional- and Communications skills) and measures what the students have learnt in supervision by means of a 4-point response scale ranging from 1 (strongly disagree) to 4 (strongly agree). The FESS measures students' ability to document nursing work, patient and family member involvement in the care as well as students' perceptions of the influence of clinical supervision. The scale uses a 4-point Likert scale from 1 (strongly disagree) to 4 (strongly agree).

\subsection{Data Analysis}

The data were analysed using the Statistical Package for the Social Sciences (SPSS) for Windows version 20.0 [18]. Descriptive statistics and reliability were examined for all scales followed by factor analysis with varimax rotation to reduce the number of underlying items. The existing sub-scale labels were retained. We created medians for each of the instruments and quartiles for each of the factors. Demographic information (i.e., age, sex, previous work experience, supervision experience such as frequency, location, context, duration of session and appropriateness) was also collected. A $p$-value $<0.05$ was deemed significant. The difference in the responses between Time 1 and Time 2 was measured by the Mann-Whitney U-test [19]. Reliability was measured by means of Cronbach's alpha. The total score for the MCSS was 0.80 and for the ESS 0.93, while in the FESS Documentation was 0.87 , User involvement 0.89 and Influence of supervision 0.87 . The Spearman rank correlation coefficient $(r)$ was used to calculate correlations between the factors.

\subsection{Ethical Considerations}

Ethical approval was granted by the principal tutor and the dean of the Faculty of Health Sciences, Buskerud and Vestfold University College, Norway. The BSN students who participated were provided with verbal and written information about the study and signed their informed consent. All of the students agreed to participate, having being informed of their right to decline, to withdraw at any time and assured of confidentiality. The Helsinki declaration guidelines [20] were adhered to.

\section{Results}

\subsection{Demographic Characteristics of the Participants, Frequency of Sessions and Supervision Context}

The demographic characteristics of the participants are presented in Table 1. The majority was female (93\%). The median age of the sample was 24 years at Time 1 and 25 years at Time 2, while 38 had previous work experience at Time 1 and 35 at Time 2. The clinical setting at Time 1 was the medical and the surgical department. At Time 2 it was home nursing care and psychiatric care. 40\% (Time 1) and 31\% (Time 2) of the students reported that the duration of contact with their supervisor was between 15 - 30 minutes. 51.5\% (Time 1) and 45.8\% (Time 2) reported that the supervision was not sufficient. The response rate was $86.8 \%$ (Time 1) and 93\% (Time 2).

\subsection{Comparing Students' Competence Development between the Second and Third Year of Clinical Education}

Table 2 presents differences between the students' development at Time 1 and Time 2 by means of factor medians and quartiles in the scales. Differences between the two measurements indicate that the students' competence development was related to the factors Improved care/skills and Importance of clinical supervision ( $p$-value < 0.047). A comparison of the factors in the ESS revealed that the factor Professional skills differed over the course of the two years, increasing from 32 to 33 (ns). 
Table 2. Descriptive data and comparisons between Time 1 and Time 2 for the BSN students’ development.

\begin{tabular}{|c|c|c|c|}
\hline & 2012 & 2013 & \\
\hline & Medians (Q1, Q3) & Medians (Q1, Q3) & p-values* \\
\hline \multicolumn{4}{|l|}{ MCSS } \\
\hline Trust/rapport time & $21(20.0,23.0)$ & $21(18.0,22.0)$ & 0.217 \\
\hline Supervisor advice/support & $24(21.0,27.3)$ & $24(20.0,27.3)$ & 0.579 \\
\hline Improved care/skills & $28(24.5,32.0)$ & $30(26.5,33.0)$ & 0.113 \\
\hline Importance of CS & $11(10.0,13.0)$ & $12(10.0,14.0)$ & $0.047 *$ \\
\hline Finding time & $12(10.0,14.0)$ & $12(9.0,13.0)$ & 0.494 \\
\hline Personal issues & $10(8.0,11.0)$ & $10(9.0,11.0)$ & 0.475 \\
\hline Reflection & $12(12.0,14.5)$ & $12(11.0,13.0)$ & 0.455 \\
\hline \multicolumn{4}{|l|}{ FESS } \\
\hline \multicolumn{4}{|l|}{ Influence of supervision } \\
\hline Supportive yet challenging relationship & $17(12.8,18.0)$ & $14(13.0,18.0)$ & 0.175 \\
\hline Preparatory and confirming professional relationship & $9(7.8,10.0)$ & $8(6.0,10.3)$ & 0.160 \\
\hline \multicolumn{4}{|l|}{ Documentation } \\
\hline Increased patient participation & $14(12.0,16.0)$ & $13(11.0,15.3)$ & 0.196 \\
\hline Increased communication and documentations skills & $12(10.0,14.0)$ & $11(10.0,13.0)$ & 0.354 \\
\hline \multicolumn{4}{|l|}{ User involvement } \\
\hline Preserving integrity & $16(15.0,16.0)$ & $16(14.0,16.0)$ & 0.109 \\
\hline Enabling participation by patients and family members & $11(9.5,12.0)$ & $11(9.9,12.0)$ & 0.501 \\
\hline \multicolumn{4}{|l|}{ ESS } \\
\hline Interpersonal skills & $36(30.9,41.0)$ & $35(32.0,39.0)$ & 0.477 \\
\hline Professional skills & $32(28.8,37.0)$ & $33(29.0,36.0)$ & 0.500 \\
\hline Communications skills & $10(9.0,11.0)$ & $10(8.8,11.0)$ & 0.338 \\
\hline
\end{tabular}

${ }^{*} p<0.0 .5$, CS $=$ clinical supervision, *Mann-Whitney’s U-test.

\subsection{Correlation Analysis}

Inter correlations among the major study variables are presented in Table 3. The evaluation of CS revealed a moderate positive significant correlation between the factor Trust/Rapport Time and the variables included in the FESS factors; User involvement (Preserving integrity $r=0.36$ and Enabling participation by patients and family members $r=0.36)$. Documentation was strongly correlated with Increased patient participation $(r=0.42)$, Increased communication and documentation skills $(r=0.44)$, Influence of supervision $(r=0.67)$, Supportive yet challenging relationship ( $r=0.68)$, Preparatory and confirming professional relationships $(r=0.49)$ and with the ESS factors (Interpersonal- $(r=0.51)$, Professional $-(r=0.40)$ and Communications kills $(r=0.39)$. The Influence of CS showed a positive correlation between Interpersonal skills $(r=0.53)$, Professional- $(r=0.40)$ and Communication skills. There was also a significant correlation between Reflection and Interpersonal skills (0.48).

\section{Discussion}

The aim of this study was to evaluate BSN students' views of professional development after CS during their undergraduate education. An additional aim was to illuminate how competence development was related to the WHO Patient Safety Educational Model. 
Table 3. Spearman's correlation between factors.

\begin{tabular}{|c|c|c|c|c|c|c|c|}
\hline MCCS & $\begin{array}{c}\text { Trust/rapport } \\
\text { time }\end{array}$ & $\begin{array}{c}\text { Supervisor } \\
\text { advice/support }\end{array}$ & $\begin{array}{l}\text { Improved } \\
\text { care/skills }\end{array}$ & $\begin{array}{l}\text { Importance } \\
\text { value of CS }\end{array}$ & $\begin{array}{l}\text { Finding } \\
\text { time }\end{array}$ & $\begin{array}{l}\text { Personal } \\
\text { issues }\end{array}$ & Reflection \\
\hline \multicolumn{8}{|l|}{ FESS } \\
\hline \multicolumn{8}{|c|}{ User involvement } \\
\hline $\mathrm{F} 1$ & $0.360^{* *}$ & $0.433 * * *$ & $0.350 * *$ & -0.164 & -0.244 & 0.159 & $0.229 *$ \\
\hline F2 & $0.358^{* *}$ & $0.433 * * *$ & 0.244 & -0.084 & $-0.324 *$ & 0.014 & 0.091 \\
\hline \multicolumn{8}{|c|}{ Documentation } \\
\hline $\mathrm{F} 1$ & $0.425^{* * *}$ & $0.482 * * *$ & $0.321^{*}$ & -0.076 & 0.134 & 0.112 & 0.031 \\
\hline $\mathrm{F} 2$ & $0.442 * * *$ & $0.559 * * *$ & $0.348^{* *}$ & -0.130 & $0.276^{*}$ & 0.191 & 0.145 \\
\hline \multicolumn{8}{|c|}{ Influence on supervision } \\
\hline $\mathrm{F} 1$ & $0.672 * *$ & $0.804 * * *$ & $0.594 * * *$ & $-0.346 * *$ & $-0.314^{*}$ & 0.248 & $0.370^{* *}$ \\
\hline F2 & $0.486^{* * *}$ & $0.589 * * *$ & $0.431^{* * *}$ & -0.239 & $-0.362 * *$ & 0.237 & $0.272 *$ \\
\hline \multicolumn{8}{|l|}{ ESS } \\
\hline \multicolumn{8}{|c|}{ Effect of supervision } \\
\hline $\mathrm{F} 1$ & $0.513 * * *$ & $0.629 * * *$ & $0.529 * * *$ & $-0.307 *$ & 0.190 & $0.276^{*}$ & $0.477^{* * *}$ \\
\hline F2 & $0.395 * *$ & $0.414 * * *$ & $0.350 * *$ & -0.138 & -0.192 & 0.157 & $0.277 *$ \\
\hline F3 & $0.388^{* *}$ & $0.444 * * *$ & $0.326^{*}$ & -0.212 & -0.185 & 0.119 & $0.307^{*}$ \\
\hline
\end{tabular}

\subsection{Improved Development after CS}

Competence was increased in the following factors; Improved care/skills, Professional skills and the Importance value of CS. The BSN students' development was related to improved care and awareness of interpersonal skills. Improved care/skills is associated with the formative functions of CS [21], where the supervisee considers that CS has improved her/his delivery of care. Learning professional skills in CS involves items such as being able to explain a situation, help the patient to describe her/his feelings, as well as the ability to understand and support others. The Professional skills factor consists of items such as knowing when to request advice from colleagues, ability to work in interdisciplinary teams and inform others about things that do not work properly. The Interpersonal skills factor concerns gaining a professional identity and an ethical stance, which enable students to assume responsibility for the patient and ward activities. Interpersonal skills also involve being able to "face" the patient, listen, see the patient's needs and to plan the care together with her/him, which is in accordance with previous research on CS [5]-[7] [9]. There is also a positive correlation between Improved care/skills and Professional skills (Table 3).

The BSN students reported a greater insight into the Importance value of CS from Time 1 to Time 2. The results of this study demonstrate that $61.5 \%$ (Time 1) and $54.4 \%$ (Time 2) of the students stated that the duration of contact with their supervisor was less than 30 minutes per week, while $51.5 \%$ (Time 1) and $45.8 \%$ (Time 2) of the students found the supervision insufficient. Comparison of the results from Time 1 and Time 2 revealed that they were stable, thus no major improvement took place between the two measurement occasions. This outcome was unexpected and calls for attention, due to the fact that at Time 2 the data were collected one year after the first occasion, when BSN students had more experience of CS and were about to graduate, which calls for attention. At the same time, the importance of CS increased at Time 2. It can be discussed whether the BSN students would have reported a greater improvement in their professional development if they had considered the CS more sufficient. A possible explanation is that they experienced the potential of CS and regretted not having more time with their supervisors. Another argument is that CS has a greater influence on students' complex and challenging everyday clinical placement than they can identify, recognize or describe [9].

A common model for BSN students' clinical placement is the use of registered nurses employed in the clinical setting as clinical supervisors. Their role is described as guiding students from the theory of nursing to its appli- 
cation in practice [3]. In order to promote patient safety the students need the possibility to combine scientific and evidence-based knowledge. The lack of integration of theory into clinical practice has been identified in many studies [22] [23]. The supervisor also functions as a role model, teaching clinical skills as well as reflective thinking [24]. However, the competence level of supervisors varies and Jonsén et al. [24] noted the lack of opportunities for students to reflect together with their supervisors. Reflective practice is an integral part of learning [25] [26] and essential for professional development [6]. Universities in Norway have little influence on which nurses are appointed to supervise BSN students during their clinical practice. However, the Norwegian authorities are working on quality indicators for clinical practice that will hopefully improve the quality of CS [27]. It should be considered whether all supervisors are competent enough to provide support for reflection and assist the students in applying theoretical knowledge to the clinical setting. A more formal supervision qualification for supervisors has been discussed in the literature. Some countries, such as the UK, have national standards for supervising nursing students, which include requirements on training, local registration, review and annual updating of qualifications [28]. A tolerant atmosphere and visible supervisors are crucial if learning is to be maximized [29]. Consequently, it is important to set aside time for supervisors to be more visible and ensure that the culture of safety functions. BSN students' learning process is associated with how they are prepared for the clinical education and how the supervisor creates an appropriate learning environment [7]. The universities could prepare students by placing more focus on a patient-centred curriculum in which patient safety is highlighted throughout the three year bachelor programme. The use of simulation and laboratories could also be increased to help students strengthen their quality and safety competencies in quality and safety issues [30] [31]. Nurses are a core part of the changing quality and safety paradigm in healthcare [10]. Sherwood \& Drenkard [32] stated that new roles for and expectations on nurses make it necessary to transform nursing curricula and graduate competencies to match the new safety paradigm. According to Saarikoski et al. [33], there are many challenges for nurse teachers and clinical supervisors in changing inappropriate and outdated approaches and developing new practices that better meet the requirements of students' learning and patients' need to feel safe. The authors suggest that practice partners and educators should work together to determine ways of evaluating and redesigning clinical learning and CS for nursing students. There is a need for a more systematic exposure to quality and safety issues, in addition to the development of competencies to ensure patient safety [32]. The WHO [11] recommended that patient safety skills and behaviour should begin as soon as a student enters a hospital, clinic or health service. The effectiveness of qualified supervision for students' professional development must be addressed and verified by means of research. The potential of CS for facilitating students to develop interpersonal, professional and communication skills, which are essential components of patient safety, is confirmed by Table 3. From a relational perspective, the quality of the care provided may serve as a motivational factor for developing a professional identity.

\subsection{The Relationship between the Patient Safety Educational Model and the BSN Students' Improved Competence Development after Attending CS}

The components of the patient safety educational model related to the BSN students' competence development after attending CS are presented in Table 4.

The competence development reported by the students was increased ability to understand and support others, knowing when to request advice and to inform others about things that do not function properly. This can be interpreted as the learning categories: learning and teaching, using evidence, working safely and specific issues in the APSEF [13]. It also corresponds to the competence outcomes in the CPSI, i.e., contributing to a culture of safety, working in teams for patient safety and managing safety risks [14]. The development of professional identity and an ethical stance, listening to and seeing the patient's needs, helping her/him to describe feelings and planning the care together with the patient are competencies that correspond with being ethical in the APSEF [13] and optimizing human and environmental factors including patient-centred care in the CPSI [14]. Assuming responsibility for the patient and ward activities and being able to explain a situation can be interpreted as components of adverse events and the ability to communicate effectively in the APSEF [13] and as the skill to recognize, respond to and disclose adverse events and to communicate effectively to ensure patient safety in the CPSI [14], Table 4.

CS motivated the BSN students to request advice from colleagues and increased their ability to engage in interdisciplinary cooperation. They also learnt to inform others about things that do not function properly and 
Table 4. The relationship between the patient safety education model and BSN students’ improved competence.

\begin{tabular}{|c|c|c|c|}
\hline $\begin{array}{l}\text { Learning categories } \\
\text { (APSEF) }\end{array}$ & $\begin{array}{l}\text { Learning domains } \\
\text { (KSAs) }\end{array}$ & Competence outcomes (CPSI) & $\begin{array}{l}\text { BSN students' competence } \\
\text { development after CS }\end{array}$ \\
\hline $\begin{array}{l}\text { Learning and teaching (I) } \\
\text { Using evidence (I) } \\
\text { Working safely (I) }\end{array}$ & $\begin{array}{l}\text { Knowledge (I, II, III) } \\
\text { Skills (I, II, III) } \\
\text { Behaviours/attitudes } \\
\text { (I, II, III) }\end{array}$ & $\begin{array}{l}\text { Contribute to a culture of } \\
\text { patient safety (I) } \\
\text { Work in teams for patient safety (I) } \\
\text { Manage safety risks (I) }\end{array}$ & $\begin{array}{l}\text { Understand and support others (I) } \\
\text { Knowing when to request advice from } \\
\text { others (I) } \\
\text { Inform others about things that do not } \\
\text { function properly (I) } \\
\text { Ability to engage in interdisciplinary } \\
\text { cooperation (I) }\end{array}$ \\
\hline Being ethical (II) & & $\begin{array}{l}\text { Optimize human and environmental } \\
\text { factors including patient-centred } \\
\text { care (II) }\end{array}$ & $\begin{array}{l}\text { Professional identity and ethical stance (II) } \\
\text { Listen to and see the patient's needs (II) } \\
\text { Help the patient describe her/his feelings (II) } \\
\text { Plan the care together with the patient (II) }\end{array}$ \\
\hline $\begin{array}{l}\text { Adverse events (III) } \\
\text { Communicate } \\
\text { effectively (III) }\end{array}$ & & $\begin{array}{l}\text { Recognize, respond to and disclose } \\
\text { adverse events (III) } \\
\text { Communicate effectively to ensure } \\
\text { patient safety (III) }\end{array}$ & $\begin{array}{l}\text { Assume responsibility for the patient and } \\
\text { ward activities (III) } \\
\text { Ability to explain a situation (III) }\end{array}$ \\
\hline
\end{tabular}

APSEF= Australian Patient Safety Education Framework [13]. KSAs = Knowledge, skills, behaviours/attitudes [13] [14]. CPSI = Canadian Patient Safety Institute [14].

dared to assume responsibility. These important skills are related to the WHO Patient safety competencies [11], especially providing patient-centred care, communicating effectively, working in teams and contributing to a culture of safety (Table 4). By daring to assume responsibility the BSN students' ethical ability was improved [13].

According to Sullivan [10], a major national initiative in the US sought to define competencies for nursing students. The primary goal of these national guidelines was to address the challenge of providing future nurses with the knowledge, skills and attitudes (KSAs) necessary to continuously improve the quality and safety of the healthcare systems in which they work [34]. These competencies underpin The WHO curriculum guide [11] and include patient-centred care, teamwork and collaboration, evidence-based practice, quality improvement, safety and informatics. Each of these competencies is defined and explained by statements about the KSAs to be developed during nursing education programmes [10].

\subsection{Limitations of the Study}

A limitation is that this study is solely quantitative. The results might have been richer if some qualitative data had been obtained from students by means of a mixed method approach and open-ended items in the questionnaire, or through the use of interviews or focus groups in order to explore some of the issues in greater depth. Another limitation is the small sample size and it could be argued that the data were collected from just one university. A suggestion for future research is a study with a qualitative design based on questions arising from the results of this study focusing on BSN students' views of the effects of CS and its potential for enhancing patient safety.

\section{Conclusion}

The results can be used to inform undergraduate nursing education leaders, teachers and practice partners at individual, group and organisational level in order to enhance patient safety and highlight the importance of CS. The results underline the close relationship between students' professional development and patient safety competencies.

\section{Contributions}

Study design: ES, AL, KA. Data collection: AL, KA. Data analysis: ES, AL, KA. Manuscript writing: AL, KA, ES. ES supervised the study. The authors declare that there is no conflict of interest.

\section{Acknowledgements}

The authors wish to thank the nursing students and the teachers who distributed and collected the questionnaire 
for the time they invested in the study. We would also like thank Monique Federsel for reviewing the English language and Vibeke Horstmann for statistical assistance. This study was funded by the Centre for Women's, Family \& Child Health, Buskerud \& Vestfold University College, Norway.

\section{References}

[1] KD Rammeplan for Sykepleierutdanning (2008) Guidelines for the National Curriculum in Nursing Education in Norway. Kunnskaps Departementet, Ministry of Education and Research, Oslo.

[2] Lindquist, I., Johansson, I. and Severinsson, E. (2011) Evaluation of Process-Oriented Supervision of Student Nurses: A Swedish Case Study. Nursing and Health Sciences, 14, 2-7. http://dx.doi.org/10.1111/j.1442-2018.2011.00628.x

[3] Severinsson, E. (1998) Bridging the Gap between Theory and Practice: A Supervision Programme for Nursing Students. Journal of Advanced Nursing, 27, 1269-1277. http://dx.doi.org/10.1046/j.1365-2648.1998.00644.x

[4] Brunero, S. and Stein-Parbury, J. (2008) The Effectiveness of Clinical Supervision in Nursing: An Evidence Based Literature Review. Australian Journal of Advanced Nursing, 25, 86-94.

[5] Severinsson, E. (1996) Nurse Supervisors' View of their Supervisory Styles in Clinical Supervision: A Hermeneutic Approach. Journal of Nursing Management, 4, 191-199. http://dx.doi.org/10.1111/j.1365-2834.1996.tb00050.x

[6] Severinsson, E., Johansson, I. and Lindquist, I. (2014) Effects of Process-Oriented Group Supervision-A Comparison of Three Groups of Student Nurses. Journal of Nursing Management, 22, 443-451. http://dx.doi.org/10.1111/j.1365-2834.2012.01463.x

[7] Severinsson, E. and Sand, Å. (2010) Evaluation of the Clinical Supervision and Professional Development of Student Nurses. Journal of Nursing Management, 18, 669-677. http://dx.doi.org/10.1111/j.1365-2834.2010.01146.x

[8] Severinsson, E. (2014) Effectiveness and Implementation of Patient Safety Care. Journal of Nursing Management, 22, 823-824. http://dx.doi.org/10.1111/jonm.12263

[9] Amsrud, K.E., Lyberg, A. and Severinsson, E. (2015) The Influence of Clinical Supervision and its Potential for Enhancing Patient Safety-Undergraduate Nursing Students’ Views. Journal of Nursing Education and Practice, 5, 8795. http://dx.doi.org/10.5430/jnep.v5n6p87

[10] Sullivan, T.D., Hirst, D. and Cronenwett, L. (2009) Assessing Quality and Safety Competences of Graduating Prelicensure Nursing Students. Nursing Outlook Today, 57, 323-331. http://dx.doi.org/10.1016/j.outlook.2009.08.004

[11] World Health Organization (2011) Patient Safety Curriculum Guide: Multi Professional Edition.

[12] Emanuel, L., Berwick, D., Conway, J. and Combes, J. (2008) What Exactly Is Patient Safety? In: Henriksen, K., Battles, J.B., Keyes, M.A. and Grady M.L., Eds., Advances in Patient Safety: New Directions and Alternative Approaches, MD Agency for Healthcare Research and Quality, Rockville, 19-35.

[13] Walton, N.N. (2006) Developing a National Patient Safety Education Framework for Australia. Quality \& Safety in Health Care, 15, 437-442. http://dx.doi.org/10.1136/qshc.2006.019216

[14] Canadian Patient Safety Institute (2009) The Safety Competences. First Edition, Canadian Patient Safety Institute, Toronto.

http://www.patientsafetyinstitute.ca/en/toolsResources/safetyCompetencies/Documents/Safety\%20Competencies.pdf

[15] Polit, D.F. and Beck, C.T. (2013) Essentials of Nursing Research: Appraising Evidence for Nursing Practice. Eighth Edition, Lippicott, Williams \& Wilkins, Philadelphia.

[16] Winstanley, J. (2002) Manchester Clinical Supervision Scale. Nursing Standard, 19, 31-32.

[17] Severinsson, E. (2005) Clinical Nursing Supervision in Health Care. Doctoral Thesis, The Nordic School of Public Health, Göteborg.

[18] SPSS (2002) SPSS Inc. LEAD Technologies, Haddonfield, NJ, USA.

[19] Siegel, S. and Castellan, J.N. (1998) Nonparametric Statistics for the Behavioral Sciences. McGraw-Hill Inc., New York.

[20] World Medical Association Declaration of Helsinki (2008) Ethical Principles for Medical Research Involving Human Subjects. Adopted by the 59th WMA General Assembly, Seoul, October 2008. http://www.wma.net

[21] Proctor, B. (1991) Supervision: A Co-Operative Exercise in Accountability. In: Marken, M. and Payn, M., Eds., Enabling and Ensuring: Supervision in Practice, National Bureau and Council for Education and Training in Youth and Community Work, Leicester, 21-23.

[22] Hilli, Y., Melender, H-L. and Jonsén, E. (2011) The Experience of Being a Preceptor for Nurse Students in Clinical Practice-A Cross-Sectional Qualitative Study. Learning Communities: International Journal of Learning in Social Contexts, 1, 84-99. 
[23] Löfmark, A. and Wikblad, K. (2001) Facilitating and Obstructing Factors for Development of Learning in Clinical Practice: A Student Perspective. Journal of Advanced Nursing, 34, 43-50. http://dx.doi.org/10.1046/j.1365-2648.2001.3411739.x

[24] Jonsén, E., Melender, H.L. and Hilli, Y. (2013) Finnish and Swedish Nursing Students' Experiences of Their First Clinical Practice Placement-A Qualitative Study. Nurse Education Today, 33, 297-302. http://dx.doi.org/10.1016/j.nedt.2012.06.012

[25] Haugan, G., Sørensen, A-H. and Hanssen, I. (2012) The Importance of Dialogue in Student Nurses’ Clinical Education. Nurse Education Today, 32, 438-442. http://dx.doi.org/10.1016/j.nedt.2011.03.011

[26] Lilja Andersson, P. and Edberg, A-K. (2012) Swedish Nursing Students' Experience of Aspects Important for Their Learning Process and Their Ability to Handle the Complexity of the Nursing Degree Program. Nurse Education Today, 32, 453-457. http://dx.doi.org/10.1016/j.nedt.2011.05.011

[27] UHR Norwegian Association of Higher Education Institutions (2010) Fokus på praksisstudiene i helse- og sosialfagutdanningene. Rapport fra UHRs kartleggingsundersøkelse av ekstern, veiledet praksis som del av studieforløpet for 115 helse- og sosialfagutdanninger.

[28] Nursing and Midwifery Council (NMC) (2008) Standards to Support Learning and Assessment in Practice. NMC Standards for Mentors, Practice Teachers and Teachers. NMC, London.

[29] Ehrenberg, A.C. and Häggblom, M. (2007) Problem-Based Learning in Clinical Nursing Education: Integrating Theory and Practice. Nurse Education in Practice, 7, 67-74. http://dx.doi.org/10.1016/j.nepr.2006.04.005

[30] McGaghie, W., Issenberg, B., Petrusa, E. and Scalese, R. (2009) Article Review of Simulation-Based Medical Education Research: 2003-2009. Medical Education, 44, 50-63. http://dx.doi.org/10.1111/j.1365-2923.2009.03547.x

[31] Jeffries, P. (2005) A Framework for Designing, Implementing and Evaluating Simulations Used as Teaching Strategies in Nursing. Nursing Education Perspective, 26, 96-103.

[32] Sherwood, G. and Drenkard, K. (2007) Quality and Safety Curricula in Nursing Education: Matching Practice Realities. Nursing Outlook, 55, 151-155. http://dx.doi.org/10.1016/j.outlook.2007.02.004

[33] Saarikoski, M., Warne, T., Kaila, P. and Leino-Kilpi, H. (2009) The Role of the Teacher in Clinical Practice: An Empirical Study of Finnish Student Nurse Experiences. Nurse Education Today, 29, 595-600. http://dx.doi.org/10.1016/j.nedt.2009.01.005

[34] Cronenwett, L., Sherwood, G. and Gelmon, S. (2009) Improving Quality and Safety Education: The QSEN Learning Collaborative. Nursing Outlook, 57, 304-312. http://dx.doi.org/10.1016/j.outlook.2009.09.004 